\title{
Aortic root aneurysm in Takayasu arteritis syndrome: Exploration in active phase and repair in inactive phase
}

\author{
Min-Ho Song, MD, PhD, ${ }^{\text {a }}$ Tomohiro Nakayama, MD, ${ }^{\mathrm{a}}$ Keisuke Hattori, MD, ${ }^{\mathrm{a}}$ Yoshiyuki Tokuda, MD, ${ }^{\mathrm{b}}$ Yukio Mabuchi, MD, ${ }^{\mathrm{c}}$ \\ and Yuichi Ueda, MD, PhD, ${ }^{\mathrm{b}}$ Gifu and Aichi, Japan
}

It is a matter of difficult decision when to operate on aortic root aneurysm due to Takayasu arteritis because Takayasu arteritis bears in itself an inflammatory character which makes a cardiac surgeon to be careful to circumvent lethal complications such as hemorrhage, pseudoaneurysm formation, valve and suture line detachment, and paravalvular leakage. We recently cased for a case of fragile and inflamed aorta of aortic root aneurysm in Takayasu arteritis in inflammatory active phase which ended in exploration, and it was radically repaired in inflammatory inactive phase six months after steroid administration. This experience prompted us to report.

\section{CLINICAL SUMMARY}

A 39-year-old Japanese woman was admitted with suspected impending rupture of an aortic root aneurysm. She had had rheumatoid arthritis for 8 years and was taking 5 $\mathrm{mg}$ of steroids. She experienced sudden dyspnea and chest and back pain, and she sought medical help at her regional hospital. A computed tomography scan revealed a $60-\mathrm{mm}$ aortic root aneurysm with a mediastinal and pericardial hematoma (Figure 1), and she was transferred to our hospital for further evaluation and definite surgery. On admission, to Gifu Prefectural Tajimi Hospital, she was free from discomfort and pain. Her vital signs were stable, and physical examination showed a diastolic heart murmur. The laboratory examination results were normal except for an elevated C-reactive protein (CRP) of 23.92. Because there were no signs and symptoms conclusively demonstrating an impending rupture, we decided to choose a careful observation over emergency surgery in search of her underlying illness. Marfan syndrome was denied. Her illness was finally diagnosed as annuloaortic ectasia producing severe aortic regurgitation caused by Takayasu arteritis syndrome without any other stenotic or ectatic legions. Additional steroid therapy, up to 20 $\mathrm{mg}$, was begun the day after admission. She remained free

\footnotetext{
From the Department of Cardiovascular Surgery, Gifu Prefectural Tajimi Hospital, Tajimi, Gifu, Japan; Department of Cardiothoracic Surgery, Nagoya University Graduate School of Medicine, ${ }^{\mathrm{b}}$ Nagoya, Aichi, Japan; and Department of Cardiology, Nakatsugawa City Hospital, ${ }^{\mathrm{c}}$ Nakatsugawa, Gifu, Japan.

Received for publication Oct 19, 2007; revisions received Nov 4, 2007; accepted for publication Nov 12, 2007.

Address for reprints: Min-Ho Song, MD, PhD, Department of Cardiovascular Surgery, Gifu Prefectural Tajimi Hospital, 5-161 Maehata-cho, Tajimi, Gifu 507-8522 Japan

(E-mail: son-minho@pref.gifu.lg.jp).

J Thorac Cardiovasc Surg 2008; 136:1084-5

$0022-5223 / \$ 34.00$

Copyright (c) 2008 by The American Association for Thoracic Surgery doi:10.1016/j.jtcvs.2007.11.069
}

from any symptoms, and her CRP decreased steadily after the initiation of $20 \mathrm{mg}$ of steroid therapy. After 1 month of steroid therapy, aortic root replacement surgery was planned because the patient's CRP was 0.07. On opening of the patient's chest, the ascending aorta and aortic root were edematous and fragile. We discontinued the exploratory thoracotomy in view of the complications in performing root replacement in the inflammatory active phase of Takayasu arteritis. She had been carefully followed up for 6 months on an outpatient basis, and her CRP remained 0.02 to 0.05 for 6 months with $15 \mathrm{mg}$ of steroid therapy. Her aortic root aneurysm increased from $60 \mathrm{~mm}$ to $67 \mathrm{~mm}$, and her aortic regurgitation produced an enlarged left ventricle, a diastolic dimension of $72 \mathrm{~mm}$, and a systolic dimension of 50 $\mathrm{mm}$. Another radical surgery was planned, and she underwent operation 7 months after the initial exploration. The surgery was carried out in the usual manner. We found the healed and stiffened aorta, and performed the Bentall and De Bono procedure by using a composite of a 26-mm Valsalva graft and 25-mm CarboMedics prosthetic valve (CarboMedics Inc, Austin, Tex) (Figure 2). To prevent pseudoaneurysm and detachment of the graft, we used our original technique for the proximal suturing. ${ }^{1}$ The patient

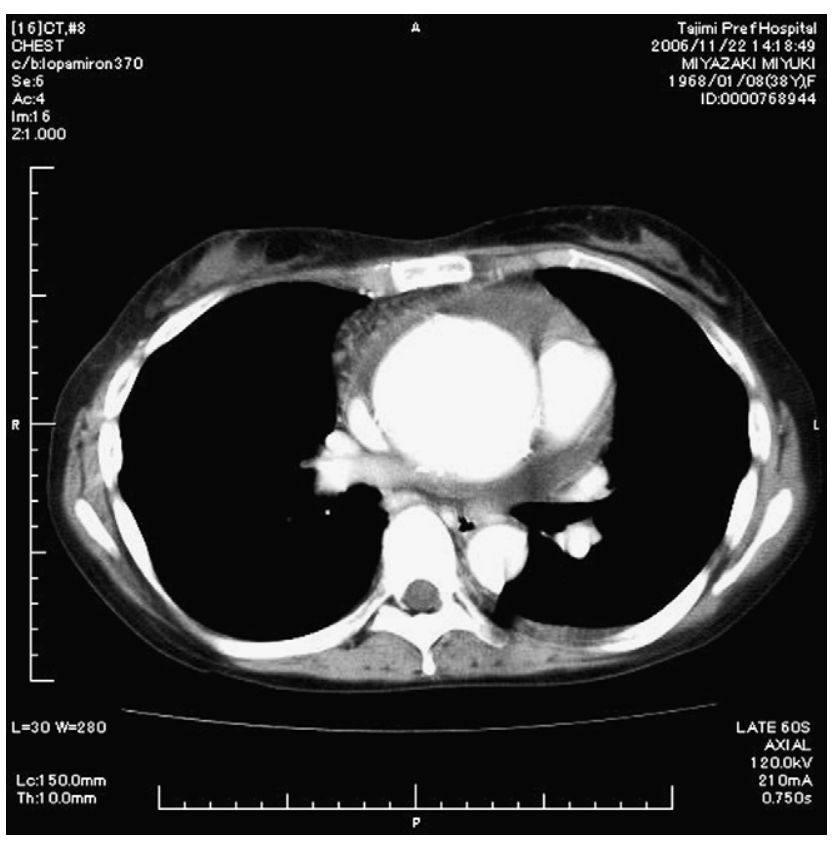

FIGURE 1. Computed tomography on admission. 


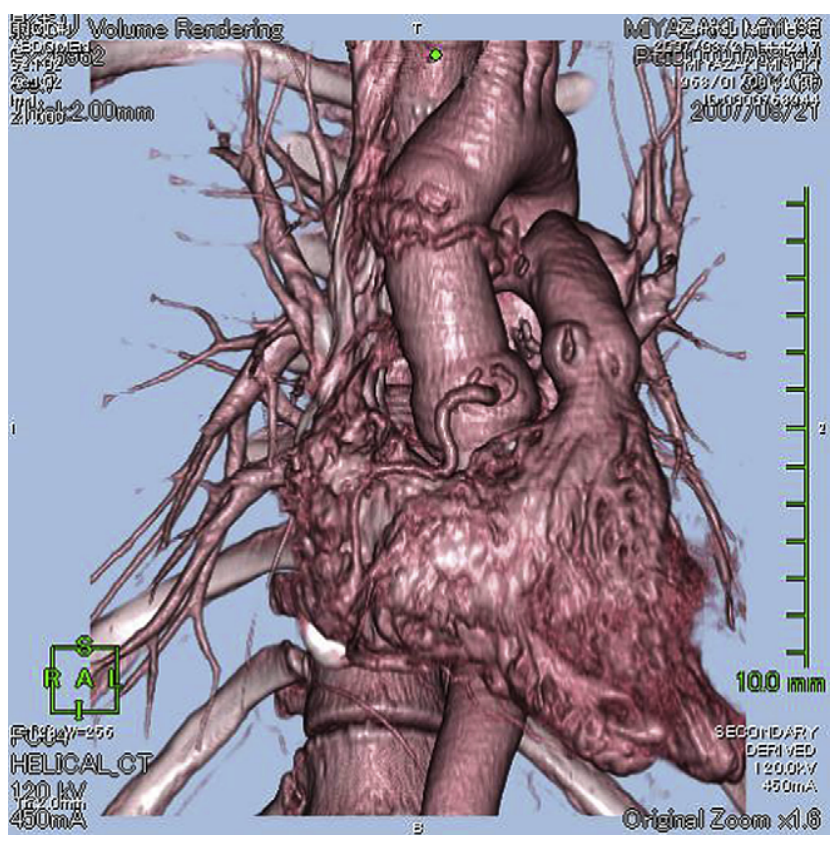

FIGURE 2. Computed tomography after surgery.

was administered $15 \mathrm{mg}$ of steroids immediately post-surgery. She had a good recovery and was discharged 10 days post-surgery.

\section{CONCLUSIONS}

Even when Takayasu arteritis is controlled by steroid therapy, the aorta can be in an active inflammatory phase. Although Amano and colleagues ${ }^{2}$ succeeded in treating 2 out of 8 patients with acute inflammatory Takayasu by applying circumferential Teflon felt to the proximal sutures, using the Carrel patch technique in coronary anastomoses, and topically applying fibrin glue, it is usually too risky to perform surgery in a patient with Takayasu arteritis during acute inflammation because of potential valve and graft detachment. Matsuura and colleagues ${ }^{3}$ reported that 10 of 90 patients in a series had evidence of acute inflammation during operation, and 4 of these 10 patients developed valve and graft detachment. Takayasu arteritis was disguised by a normal CRP, and this case showed that patients with Takayasu arteritis should be treated preoperatively with steroid therapy for at least six months, making sure that the CRP remains negative during that time.

\section{References}

1. Song MH, Tokuda Y, Ueda Y. A novel method of proximal suturing of CarboSeal: aorta folded-over technique. Gen Thorac Cardiovasc Surg. 2007;55:270-1.

2. Amano J, Suzuki A, Tanaka H, Sunamori M. Surgical treatment for annuloaortic ectasia in Takayasu arteritis. Int J Cardiol. 1998;66:S197-202.

3. Matsuura K, Ogino H, Kobayashi J, Ishibashi-Ueda H, Matsuda H, Minatoya K et al. Surgical treatment of aortic regurgitation due to Takayasu arteritis. Circulation. 2005;112:3707-12.

\title{
Partial left pulmonary artery sling associated with multiple ventricular septal defects: A rare congenital anomaly
}

\author{
C. Tissot, MD, J. R. Darst, MD, A. K. Kaza, MD, A. K. Younoszai, MD, and E. da Cruz, MD, Denver, Colo
}

Partial anomalous left pulmonary artery is a rare condition. We present a case of partial left pulmonary artery sling, associated with multiple ventricular septal defects, where the lower posterior branch arises from the right pulmonary artery.

\section{CLINICAL SUMMARY}

A premature male infant of 30 week's gestation was delivered abdominally in an outreach hospital. He was intubated

\footnotetext{
From the Heart Institute, Department of Pediatrics, The Children's Hospital of Denver, University of Colorado at Denver \& Health Sciences Center, Denver, Colo. Received for publication Oct 22, 2007; accepted for publication Dec 14, 2007. Address for reprints: Eduardo da Cruz, MD, Director, Cardiac Intensive Care Unit, Associate Professor of Pediatrics, The Children's Hospital of Denver, University of Colorado at Denver \& Health Sciences Center, 13123 E 16th Ave, Aurora-Denver, CO 80045 (E-mail: dacruz.eduardo@tchden.org).

J Thorac Cardiovasc Surg 2008;136:1085-7

0022-5223/\$34.00

Copyright (c) 2008 by The American Association for Thoracic Surgery doi:10.1016/j.jtcvs.2007.12.054
}

in the delivery room, and surfactant was administered. Clinical examination revealed an imperforate anus, a cleft palate, the presence of two neonatal teeth, and dysmorphic facies. A malformative workup showed a small right pelvic kidney, severe left hydronephrosis, multiple "swiss cheese" ventricular septal defects, and a patent ductus arteriosus with bidirectional shunting. Neonatal hypothyroidism was also diagnosed. The neonate underwent a colostomy soon after birth and was extubated on the fourth day after birth. His clinical evolution during the first weeks of life showed progressive increased work of breathing with clinical signs of heart failure, motivating his transfer to our center.

Echocardiography performed on admission at 6 weeks after birth demonstrated the multiple ventricular septal defects with low velocity left-to-right shunt. Short-axis views of the heart demonstrated a main pulmonary artery branching normally anterior to the trachea into right and left pulmonary 